\title{
Sistemas Axiológicos del siglo XXI: Un collage. El declive de los sistemas axiológicos de creencias y la coexistencia de creencias variopintas en el mercado espiritual
}

\author{
Axiological Systems in the XXI century: A Collage. The downfall of \\ axiological systems based on beliefs and the co-existence of varied beliefs \\ in the spiritual market
}

\begin{abstract}
Resumen
Pretendemos mostrar como los sistemas axiológicos de creencias provenientes de las religiones no están vigentes en la actualidad. Para ello mostramos algunos datos del Banco Mundial que muestran como los sistemas heterónomos de creencias no funcionan como orientadores de la vida personal y social del individuo. También facilitamos información sobre la disminución de los que se autoadscriben como pertenecientes a un sistema de creencias y además demostramos mediante las estadísticas que no existe relación entre autoadscribirse como miembro de un sistema de creencias y mantener unas determinadas creencias. Clarificamos la noción de creencia comúnmente utilizada como supuesto acrítico y otros usos del lenguaje corriente y del lenguaje científico. Utilizamos estadísticas de Catalunya, España, y de algunos países de Europa y América. Concluimos que si los sistemas axiológicos de los individuos no vienen determinados por las religiones, entonces ¿qué sistemas axiológicos tenemos que sean capaces de cohesionar y motivar los individuos hacia fines valiosos comunes?
\end{abstract}

Palabras clave: Sistemas Axiológicos. Creencias. Religión. Cualidad humana. Estadísticas. España. Católico.

\begin{abstract}
We aim to show why axiological systems coming from religion are not operative currently. To do this we exhibit World Bank data showing that heteronomous systems of beliefs are not dominant to orient the personal and social life of individuals. We also communicate the declining numbers of those that register themselves as believers and we also reveal that there is no relationship between registering oneself as a believer in an axiological system and effectively holding and "believing" the beliefs of that axiological system. We clarify the common use of the term belief as a non-critical assumption, and other uses of the term in natural language and scientific language. We use statistical data for Catalonia, Spain and some countries of Europe and America. We conclude by asking if individuals' axiological systems are not determined by religions, then What axiological systems do we have able to cohere and motivate individuals towards valuable common futures?
\end{abstract}

Keywords: Axiological systems. Beliefs. Religion. Human Quality. Statistics. Spain Catholic

Artigo recebido em 02 de novembro de 2012 e aprovado em 21 de dezembro de 2012.

* Licenciada en Dirección y Administración de Empresas y MBA por ESADE y Master CEMS. También ha cursado estudios de MBA en Insead (Francia) y estudios de master de investigación en ESADE. Actualmente está desarrollando su doctorado en ESADE sobre la cualidad humana en el management. País de origem: Espanha. E-mail: queralt@gmail.com 
No sabemos a dónde vamos, sino tan sólo que la historia nos ha llevado hasta este punto .... Sin embargo, una cosa está clara: si la humanidad ha de tener un futuro, no será prolongando el pasado o el presente. Si intentamos construir el tercer milenio sobre estas bases fracasaremos.

(Hobsbawn 1998)

\section{Preliminar}

En ESADE (Escuela Superior de Administración y Dirección de Empresas), Universitat Ramon Llull estamos preocupados por investigar respuestas a la problemática axiológica de la sociedad del conocimiento. Una problemática que por efecto de la globalización se ha extendido y se profundizará en todas las partes del planeta. Y esto es así, porque en la gestión de empresas se requieren seres humanos creativos capaces de comportarse socialmente más que nunca, capaces de establecer nexos de comunicación y colaboración constantes. Este artículo pretende profundizar en la comprensión de los sistemas axiológicos de creencias religiosos y mostrar una ilustración, utilizando el caso de España, de una situación de desarticulación del sistema axiológico que no tiene marcha atrás.

\section{Introducción}

El propósito de este artículo es presentar una radiografía del estado actual de las creencias religiosas, mostrando su declive e incluso su extinción, en el caso de España, como sistemas de valoración de la realidad. Es decir, defendemos que la religión ya no es la base del sistema axiológico de los individuos de las sociedades española y catalana no que se extingan las religiones, pueden seguir existiendo, pero sin ser la base del sistema axiológico. Comprender la situación es clave con el fin de apostar por un enfoque de desarrollo de nuevos métodos de cultivo de la cualidad humana y de la formación de sistemas axiológicos, acorde con el siglo XXI y alejados de la creencias religiosas, y a la vez ser capaces de aprovechar las aportaciones e 
intuiciones de cualidad humana que emanan de estas tradiciones de sabiduría milenarias.

Defender que la valoración e interpretación por la que rigen su vida los seres humanos del mundo está mayoritariamente, con matizaciones por la heterogeneidad social, fuera de los patrones de la valoración religiosa, es decir, que está fuera de la creencia religiosa no es en sí contrapuesto con que se pueda argumentar que en determinadas zonas pueda existir un aumento de algunas religiones. Sin embargo, no es nuestro objetivo discutir este posible aumento, sino demostrar que los sistemas de valores basados en creencias no funcionan ya, y que lo que en general miden las estadísticas como signo de religiosidad, son creencias autónomas de los individuos al mismo nivel que otras creencias presentes en la actualidad, como veremos, por ejemplo comparable con las creencias en la astrología, o el mal de ojo entre otras. Es decir, estas estadísticas no miden las creencias heterónomas vigentes en las sociedad.

La segunda aportación de este artículo consiste en clarificar la noción de sistema de creencias y la noción de creencia personal, comúnmente supuestos acríticos, valorando la autonomía y la heteronomía de la creencia, es decir, su carácter configurador individual y su carácter colectivo. Finalmente, clarificamos las estadísticas referentes a las creencias para el caso de España.

\section{La interpretación y la valoración de la realidad en una sociedad de individuos}

Hobsbawn (1998) argumenta que el 80\% de la población mundial sintió que la Edad Media se terminaba en los años sesenta. Explicaba que el cambio social más drástico y de mayor alcance en el siglo XX ha sido el fin de la preponderancia de la agricultura como forma de ganarse la vida. Y este cambio es tan radical, porque termina con 15,000 años de dominio de esta forma de vida en la tierra (EIBL-EIBESFELDT, 1996), 15,00o años en los que aprendimos 
a organizarnos y a cohesionarnos como grupo para sobrevivir. Desde el Neolítico, la mayoría de los seres humanos había vivido de la tierra, los animales domésticos o la pesca.

En el año 2005, por primera vez en la historia de la humanidad, más del $50 \%$ de la población mundial habitaba en las urbes. Un porcentaje que no cesa de crecer debido a las tasas de crecimiento de la India, China y Brasil, países que actualmente representan aproximadamente el 40\% de la población mundial. En el año 1960 el 84\% de la población China vivía en zonas rurales, en el 2005 había disminuido al 59\%. En India las estadísticas no son tan espectaculares, pasando del $82 \%$ al $71 \%$, pero son también significativas, es por ello que las tasas de urbanización presentan todavía potencial de crecimiento. España y México presentan datos parecidos, en 1960 había respectivamente el 44\% y el 49\% de población viviendo en el medio rural y en el 2005 sólo el 23\% (WORLD BANK, 2011).

Si estudiamos el impacto de la agricultura en la riqueza del país también vemos que su importancia ha disminuido de manera relevante. En España la agricultura representaba el 10\% del Producto interior Bruto en el año 1970, y en el año 2009 había descendido hasta el 2,7\%. En México representaba el 12\% en 1970 y el 4,3\% en el año 2009. En 1970 la media de la zona euro era del 7,4\% y en el año 2009 era del 1,5\%. Los países latino americanos y caribe pasaron del 12,6\% en 1970 al 6,1\% en 2009. La zona del sudeste asiático representaba el 41,5\% en 1970 y el 17,8\% en 2009. En la África subsahariana el PIB proveniente de la agricultura representaba el $19,5 \%$ en 1970 y el 12,3\% en 2009. India representaba el 42,3\% en 1970 y el 17,1\% en 2009. China representaba el 35,2\% en 1970 y en el 2009 sólo el 10,3\% (WORLD BANK, 2011). Como vemos el proceso de declive es acentuado y global.

El retroceso de la agricultura y las migraciones del campo a la ciudad provocan un aumento de otras profesiones y un ímpetu por mejorar el nivel 
educativo de la población. Las mujeres entran a formar parte del mercado de trabajo en grandes proporciones y la organización del hogar empieza a sufrir cambios, unos cambios que se han ido extendiendo paulatinamente. Al proceso de industrialización y concentración urbana ha seguido el proceso de globalización, que ha llegado a todas las partes de la Tierra. Globalización, no sólo entendida como los procesos por los cuales los estados se encuentran ligados en estructuras transnacionales que influencian su orientación, poder e identidad (BECK, 1998) sino también la globalidad entendida como aquella conexión mediante los sistemas de información en la que nada que pase en cualquier parte del mundo es extraño a nosotros, sino que nos afecta y debemos prever sus consecuencias, quedando así nuestro quehacer diario en un eje global-local (BECK, 1998). También el aumento de las migraciones ha creado sociedades cada vez más parecidas y paradójicamente internamente más diversas, así la globalización se ha transformado y adaptado a las idiosincrasias locales (GEERTZ, 2000).

Esta globalidad, no sólo ha significado la expansión de la sociedad de riesgo, sino también una consolidación del sistema social de individualización (BECK, 1992). Este sistema implica una ruptura total con las valoraciones y los sistemas procedentes de las tradiciones de las épocas industriales y anteriores. Los modos de vida que venían fijados por las religiones, el país, la familia, la clase cesan de ser relevantes, el estado se erige como referente (ELIAS, 1990). El sujeto cobra protagonismo y es responsable por construir su vida y su destino. Así su vida se define como una serie de elecciones, nunca pre-establecidas y en continuo cambio. La autoridad para decidir es exclusivamente suya. La individualización produce un individuo autónomo que no acepta formulaciones externas como inamovibles o apodícticas, no está subordinado a patrones colectivos determinados (BECK; BECK-GERNSHEIM, 2001). La individualización reside en transformar este algo "dado" en una "tarea” con sus respectivas consecuencias (BAUMAN, 2004). 
El fenómeno de la individualización no significa la generación de una sociedad de egoístas, no significa la finalización del altruismo, sino todo lo contrario. Cuando más diferenciación funcional existe entre los individuos más relación entre ellos es necesaria (ELIAS, 1990). Así, una sociedad individualizada creativa requiere seres humanos capaces de comportarse socialmente más que nunca, capaces de establecer nexos de comunicación y colaboración constantes con otros individuos (BECK; BECK- GERNSHEIM, 2001).

Por tanto, la individualización va más allá de la emancipación promulgada por la ilustración, en donde se proclamaba la superioridad de la razón y la libertad del individuo para vivir la vida no sujeto a los lazos que la comunidad, la iglesia o el país imponía. Esta individualización en la que vivimos va más allá de una elección, significa crear, construir una identidad, un modo de vida que merezca la pena ser vivido. Esta situación provoca nuevas vicisitudes, esto es, las viejas certezas con la que se estructuraba la vida y daban sentido, ya no existen. Es decir, las interpretaciones y valoraciones de la realidad provenientes de sistemas heterónomos donde hay una revelación, en el caso de las religiones, o un descubrimiento de la naturaleza de las cosas, en el caso de la ideologías, que explicitan y fijan como debe ser el proyecto personal y colectivo ya no son aceptadas mayoritariamente.

Así, aunque existan diversidad de religiones y de proyectos ideológicos, estos no someten a los individuos de estas sociedades, precisamente porque existe este proceso de individuación, descrito y destacado por múltiples sociólogos. Por tanto, los sistemas axiológicos de motivación y valoración colectiva provenientes de la religiones o de las ideologías ya no están vigentes en el ámbito de la colectividad. Ahora, hay una multitud de opciones que se presentan y se crean, no son impuestas socialmente, sino que el individuo escoge libremente. La falta de patrón de decisión, porque no hay orientaciones colectivas impuestas, genera, muchas veces, una conceptualización negativa del 
proceso de autonomía, porque se compara con "la facilidad" de un sistema de creencias fijado heterónomamente. Esta conceptualización negativa del proceso de individualización es presentado muchas veces como una anomia, como un relativismo degenerado, en que todas las opciones valen. Nada más lejos de la realidad, sólo aquello que signifique verdadera creación personal con lazos a los otros individuos puede funcionar y por tanto, no todo vale. A veces también se habla de crisis de valores, una frase que creemos no es apropiada, porque induce a pensar que los valores están en crisis, como si se supiera cuáles son estos valores. Lo que está en crisis son las personas que no tienen sistemas axiológicos a los que adherirse creados para las condiciones de vida del siglo XXI.

Es importante seguir clarificando que el concepto de individualización, aunque pudiera evocar la concepción neoliberal del individuo, como sujeto autárquico y con capacidad de elección, que es autosuficiente y que no tiene ningún tipo de obligación versus los otros, ni la sociedad, y que por ello hace peligrar el mismo sentido de la sociedad, no es adecuado. El proceso de individualización es una característica estructural de sociedades diferenciadas, y favorece la integración social. Esto es así porque el individuo se concibe como insuficiente y cada vez más conectado a los otros. En una sociedad en cambio continuo, el éxito de la sociedad no depende de las tradiciones sino de la capacidad recíproca de individualización y su conexión que multiplica la aparición de respuestas creativas (BECK; BECK-GERNSHEIM, 2001).

Dada esta situación es de prever que los sistemas de creencias de las religiones continúen sufriendo un abandono paulatino, tal como las estadísticas recientes demuestran, e incluso posiblemente lleguen a extinguirse o a funcionar sólo en reductos muy marginales. Esto no significa que las religiones hayan muerto, sino que la determinación que ejercían en el individuo ha dejado de suceder, y esto es así porque ya no son socialmente aceptadas como las normas a las que someterse, es decir, el individuo es libre de aceptar cualquier proyecto religioso, ideológico, o de cualquier otro tipo. Así, la heteronomía, el 
proyecto personal y colectivo que es revelado por Dios, en el caso de las religiones, no es impuesta ni aceptada socialmente. Sin embargo, un fenómeno etiquetado como religioso puede llegar a incrementarse, a extenderse, por ejemplo por efecto de transvase de un sistema heterónomo a otro, pero no será comparable a aquel sistema axiológico de las sociedades pre-industriales o industriales mixtas por dos razones, primero, porque el poder impositivo incluso coercitivo social de sumisión al proyecto revelado no existe, y segundo porque aunque todavía se den conversiones (transvases de un sistema heterónomo a otro) el "milieu" social hace posible que muchos sujetos se puedan someter a sistemas heterónomos "a medias" tal como demuestran las estadísticas para España, es decir, por libre elección el individuo ahora escoge el área que le satisface de esa religión y deja de lado cualquier otra determinación que va en contra de la creación de su modo de vida (AUGÉ, 2000). Por tanto, las religiones dejan de crear una determinación social, total, de un proyecto de vida personal y colectivo heterónomo, y se convierten en algunos casos en elección individual, parcial de una manera de vivir autónoma/heterónoma con más o menos problemas: "creencias a la carta", o en un abandono de la religión, o en caso de las conversiones de heterónomo a heterónomo (por ejemplo de Católico a Testigo de Jehová) con más margen para abandonar en un futuro el sistema de creencias al no existir la coerción social, aunque el sujeto continúe sometido a las creencias de tipo heterónomo.

En el caso que el sistema heterónomo funcione parcialmente, esta religión "light" o creencias "a la carta" pasa a coexistir al mismo nivel que otras creencias presentes en nuestra sociedad como por ejemplo son las creencias en la astrología, mal de ojo o las brujas entre otros, y esto es así porque éstas tienen la particularidad que no someten, es decir, no fijan el proyecto personal ni el colectivo, es decir, el individuo es libre de fijar su proyecto personal y no existe un proyecto colectivo dominante. Estas creencias pueden ser abandonadas y cambiadas en el momento oportuno, dependiendo de muchos factores que no estudiamos aquí. Mostraremos una ilustración numérica para el caso de España 
en el último apartado de este texto.

A pesar del anunciado declive y posible extinción, los sistemas de creencias pueden seguir funcionando en todas aquellas sociedades tradicionales que todavía viven con modos de vida pre-industriales o industriales mixtos. Además, los países no presentan sociedades homogéneas y por tanto, tal como hemos explicado, pueden existir diversas maneras de vivir los sistemas de creencias, desde un sistema de creencias que determina toda la vida del individuo, por ejemplo una conversión total a un sistema heterónomo, hasta una elección parcial que el sujeto puede decidir dejar de lado cuando considere conveniente, incluso escoger aquellas creencias que le convienen y aquellas que no.

En este último caso, el sistema de creencias ya no puede ser utilizado como estructura facilitadora de la experiencia espiritual, ya que al haberse modificado el pensar y el sentir del individuo, el sistema de creencias por el cual se vivía la espiritualidad no puede funcionar. Además, una elección parcial individual versus una heterónoma social, significa que el individuo es capaz de escoger aquello que le gusta y dejar fuera aquello que no, por tanto, el sistema de creencias se fragmenta y difícilmente puede facilitar la vida espiritual, ya que pierde coherencia y fuerza.

Así, aunque para la casi totalidad de la población sea imposible vivir una vida espiritual a través de las religiones, si pueden funcionar como medio para por ejemplo conseguir amigos, establecer relaciones fructíferas, conseguir paz interior o conocer a las personas adecuadas (CIS, 2008), y por tanto, estarán compitiendo por conseguir "clientes", como cualquier otro tipo de ofertas en el mercado, que ofrezcan productos adecuados para estas necesidades.

Utilizando las estadísticas podemos obtener aproximaciones del grado de aceptación de los sistemas heterónomos provenientes de las religiones. Así, mostramos unos datos procedentes del Banco Mundial (THE WORLD BANK, 2011) 
que nos permiten obtener una perspectiva a nivel mundial al incluir datos de España conjuntamente con otros países de Europa y América. Hemos seleccionado tres estadísticas, la primera en la que se explicita claramente una visión heterónoma del individuo, y una autónoma. Como muestran las cifras, la totalidad de los países investigados presenta una mayoría de individuos con una visión autónoma respecto a la construcción de la propia vida, mostrando claramente una no determinación por el sistema de creencias. Sólo si las contingencias de la vida son atribuidas, interpretadas y valoradas dentro de un sistema religioso (GIDDENS et al, 1996), se forma parte de un sistema de creencias religioso. El segundo y tercer gráfico muestran valoraciones de los individuos respecto a la justificación del divorcio y de la homosexualidad. El divorcio se justifica en la totalidad de los países por mayoría, siendo los más reacios Italia, México y Colombia. La homosexualidad no es tan justificable para la mayoría de los italianos y colombianos, mostrando en este caso una mayor sincronía con sistemas de creencias tradicionales. En resumen, se muestra que el proceso de individualización ha alcanzado a un gran número de países, siendo la homosexualidad una de las variables analizadas que presenta datos más negativos respecto a esta tendencia, y matizando que estas variables que evaluamos son aproximaciones al fenómeno de la individualización que presenta idiosincrasias locales y que no hemos podido analizar en la totalidad de países de la Tierra para este artículo.

\section{Tabla 1}

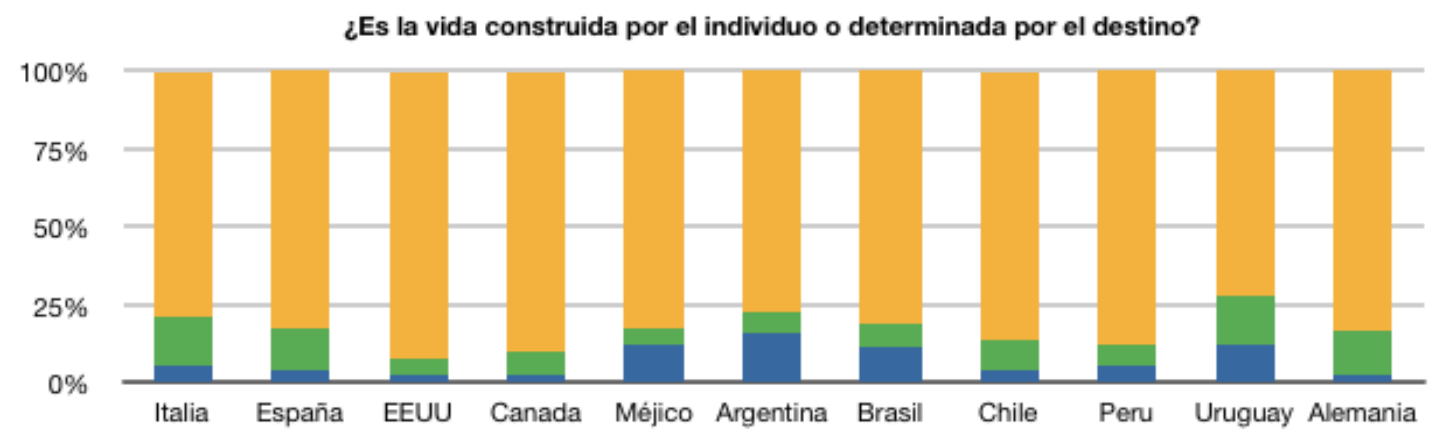

Todo está determinado por el destino Las personas diseñan su destino ellas mismas

El destino es importante (2-4)

Fuente: THE WORLD BANK, 2011 


\section{Tabla 2}

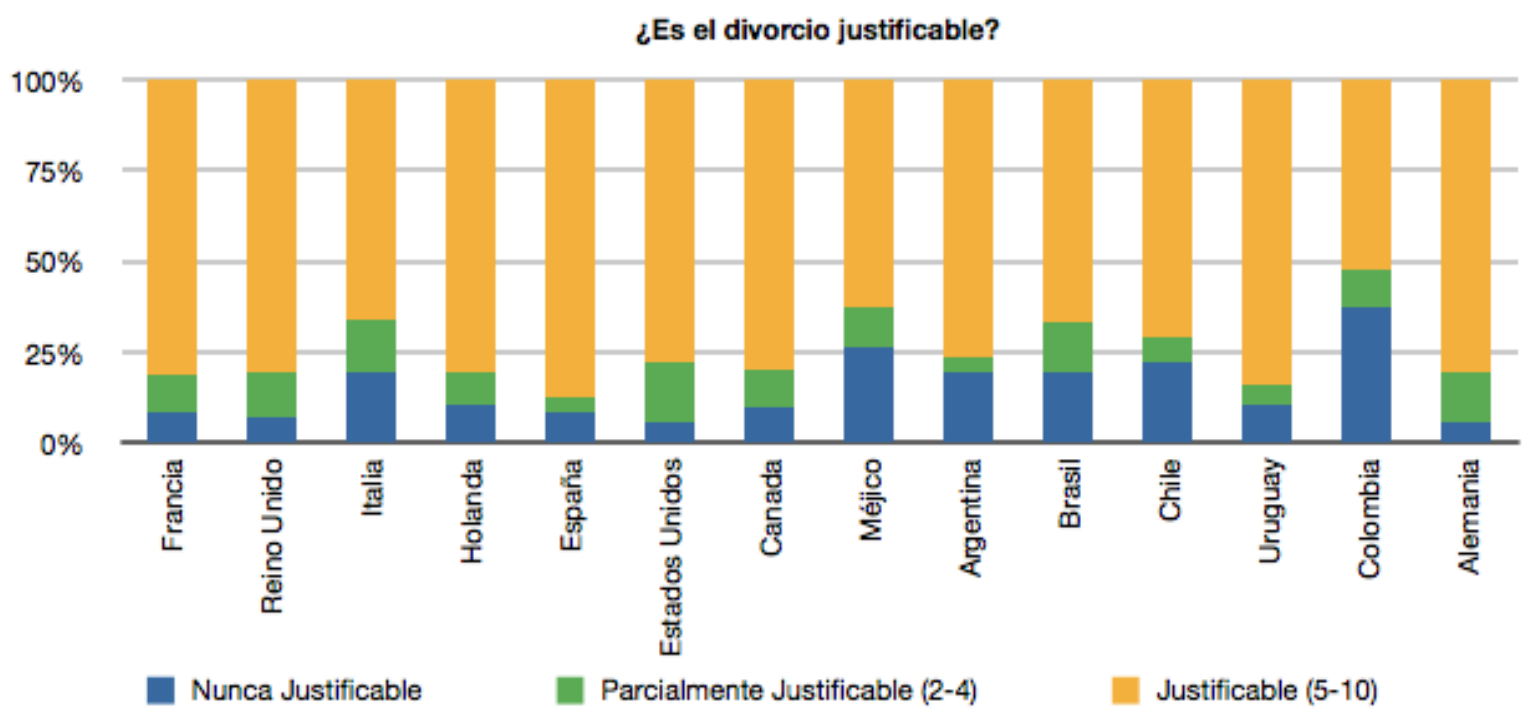

Fuente: THE WORLD BANK, 2011

Tabla 3

¿Es la homosexualidad justificable?

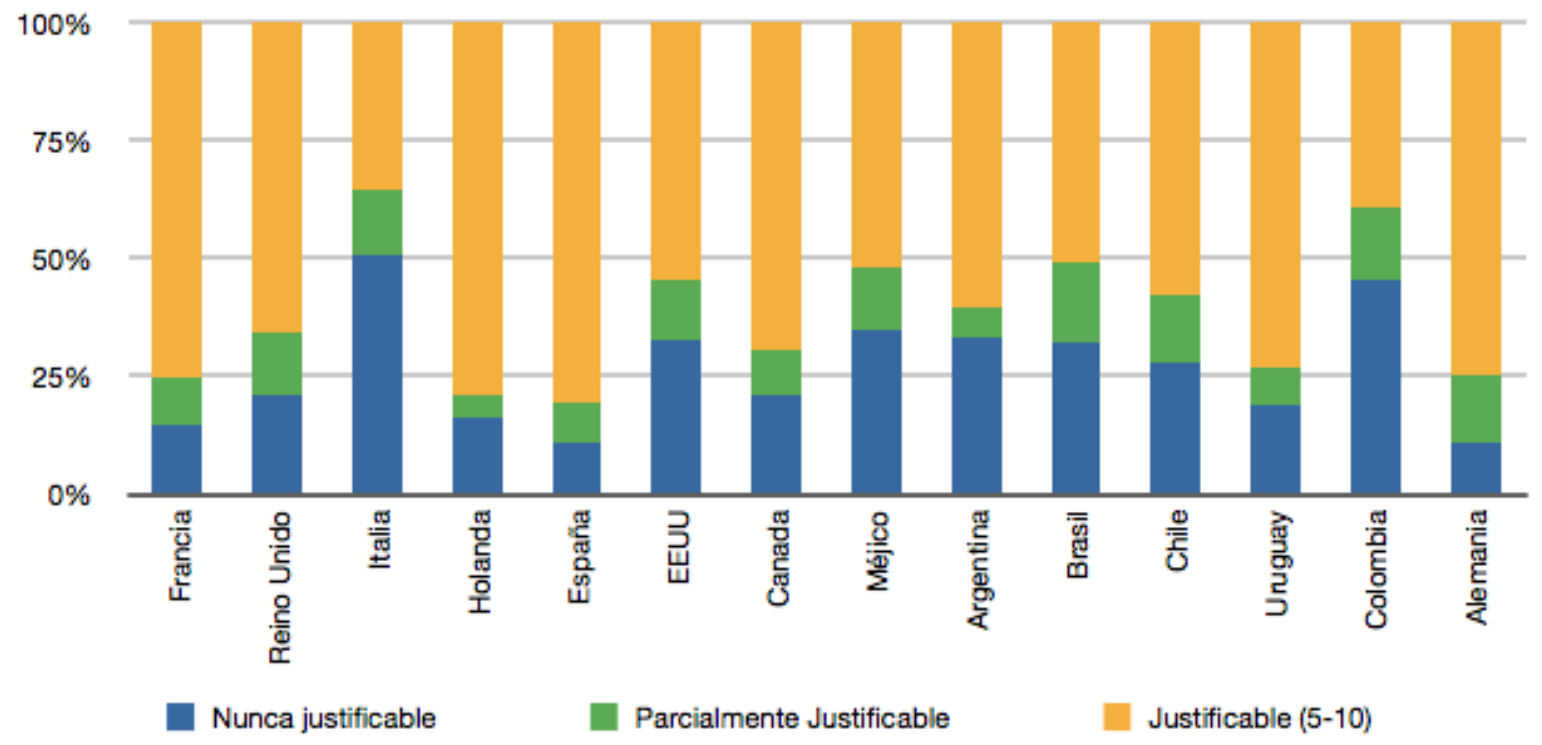

Fuente: THE WORLD BANK, 2011 
Con estas tres gráficas pretendemos reflexionar sobre lo que implican a nivel del sistema de creencias heterónomo. Estas tres gráficas demuestran una no sujeción a los valores impuestos por las tradiciones religiosas, por lo tanto, podemos afirmar que si en un sistema dejan de funcionar partes, el sistema ya no funciona. La pérdida de significación de las iglesias en Europa ha sido un fenómeno demostrado y estudiado ampliamente en Europa (ARTS; HALMAN, 2004. ESTER; MOHLER; VINKEN, 2006). Por tanto, aunque las religiones continuen, una gran mayoría de la sociedad no se adhiere al sistema. Paradójicamente, estos mismos individuos pueden seguir afirmando que son creyentes, pero al mismo tiempo son capaces de defender el divorcio y la homosexualidad como posibilidades viables y plenamente aceptables.

\section{Las creencias: supuestos acríticos, opiniones y otros. Una clarificación}

Nuestro estudio está focalizado en comprender de una manera más profunda la significación de los sistemas axiológicos basados en creencias. Tal como hemos visto, vivir sin un sistema de creencias es posible, es tal y como vivimos nuestra vida hoy en día, sin creencias de tipo heterónomo y determinista. Esto no significa que no tengamos creencias, algunos más que otros. Incluso algunos no pueden concebir su vida ni las de los otros, sin una serie de creencias más o menos fijas. Todo esto son características personales de cada uno. También se presentan aquellos que son capaces de vivir en la total duda de todo lo que les rodea, sin tener respuestas a sus preguntas como el premio Nobel de Física del 1965 Richard Feynman, quien afirma que no tiene ningún problema en vivir su vida con aproximaciones, opiniones y diversos grados de certidumbre (McGOWAN et al, 2009).

Es importante diferenciar entre creencias y supuestos acríticos, ya que estos últimos son los que predominan en la actualidad. Las creencias de las religiones son heterónomas, el sujeto se somete a un proyecto personal y social 
determinado y legitimado por un poder divino. Las creencias de las ideologías como el socialismo o el liberalismo también presentan las mismas características, el sujeto se somete a unas creencias heterónomas legitimadas esta vez por la naturaleza de las cosas, descubierta por la ciencia o la razón. Sin embargo, los supuestos acríticos serían todas aquellas afirmaciones, supuestos, que no son desafiados por el individuo, es decir, supuestos por los que uno transita en la vida sin cuestionarse su idoneidad. Estos supuestos son aceptados acríticamente, pero no son fijados heterónomamente, sino que por falta de discernimiento y criterio dirigen la propia vida. A continuación mostramos algunos ejemplos ilustrativos y no exhaustivos de lo que son algunos supuestos acríticos en diferentes niveles. Queda a cada uno extraer las consecuencias de estas creencias:

\section{Tabla 4}

\section{Recopilación de algunas creencias}

\begin{tabular}{|l|l|}
\hline A nivel social & $\begin{array}{l}\text { El mercado es el sistema más eficiente para asegurar la prosperidad } \\
\text { La democracia asegura la justicia } \\
\text { Los monopolios públicos deben ser suprimidos, etc. }\end{array}$ \\
\hline A nivel empresa & $\begin{array}{l}\text { El buen trabajo se recompensa más pronto o más tarde } \\
\text { Los buenos trabajadores son los que ascienden en la jerarquía laboral } \\
\text { Los sindicatos defienden los derechos de los trabajadores, etc. }\end{array}$ \\
\hline A nivel familia & $\begin{array}{l}\text { Si tengo una pareja seré feliz } \\
\text { Los padres tienen que ser amigos de sus hijos } \\
\text { La familia está por delante de todo, etc. }\end{array}$ \\
\hline A nivel personal & $\begin{array}{l}\text { El dinero como objetivo es lo más importante } \\
\text { Preocuparse por la felicidad de uno es primordial } \\
\text { Los amigos son para toda la vida, etc. }\end{array}$ \\
\hline
\end{tabular}

Fuente: Compilación realizada por Queralt Prat-i-Pubill

Además de utilizar el vocablo creencia para referirnos a lo que comúnmente son supuestos acríticos, también utilizamos el término creencia 
para referirnos a opiniones, deseos, expectativas, esperanzas, intenciones, dudas, condiciones, pensamientos, ideas, entre otros. Por ejemplo: “ creo que lloverá, me pondré las botas”, “creo que si estudio lo suficiente apruebo”, “creo que el tren llegará pronto", “creo que si trabajo en este proyecto tendré una buena experiencia”, "no creo que ganemos". En resumen, si no utilizamos los sinónimos que nos provee la lengua y siempre utilizamos la palabra creer como comodín, entonces uno podría argumentar que ino se puede vivir sin creer!. Así, hemos visto que aunque en el lenguaje corriente utilicemos el término creer, esta creencia es diferente a las creencias provenientes de sistemas axiológicos formados a través de la religión o las ideologías que estructuran el pensar y el sentir del sujeto al someterlo a una interpretación y valoración de la realidad legitimada por el poder de Dios o por el descubrimiento de la naturaleza de las cosas.

El abuso del término creer en el lenguaje corriente y la falta de uso de sinónimos no es sólo prerrogativa de la conversación corriente, sino que incluso en el lenguaje científico existe una problemática similar. Esto es así porque coloquialmente los científicos en vez de usar términos como los de: hipótesis, predecir, anticipar, augurar, prever, visionar, pronosticar, entre otros, utilizan la palabra creer. Si bien, no es doxa como sería el caso de la conversación entre legos, en este caso sería desarrollo de conocimiento científico, si es apropiado remarcar esta tendencia con el fin de clarificar, que tampoco la creencia de la que hablan los científicos es ésta que investigamos aquí.

\section{En España, las estadísticas demuestran que la interpretación y valoración de la realidad es ajena a los sistemas axiológicos basados en creencias.}

A continuación, con el uso de las estadísticas, mostraremos como las creencias provenientes de las religiones no estructuran actualmente las interpretaciones y las valoraciones de la realidad de los individuos, es decir no 
determinan el sistema axiológico de los individiuos. Estudiaremos tres partes bien diferenciadas, primero el número de personas que se autoadscriben a las religiones, segundo investigaremos si las valoraciones y las interpretaciones de los individuos siguen las doctrinas de las religiones y tercero veremos si existe relación entre la autoadscripción a un determinado sistema de creencias y las diversas creencias cristianas y si existen restos de creencias ancestrales que coexisten en las sociedades actuales. Realizaremos un análisis empezando a nivel local (Catalunya) y finalizando con el análisis de España.

En Catalunya, en el año 1989 el 30,3\% de los encuestados se declaraban practicantes, en el año 2007 sólo el 12,5\%, mostrando una evolución negativa pronunciada. El número de Católicos no practicantes en las mismas fechas aumentó de un $53,2 \%$ a un $61,1 \%$ mostrando así un transvase de practicantes a no practicantes, y también una disminución del total de Católicos del 83,5\% en 1989 al 73,6\% en 2007 (SONDEIG D’OPINIÓ CATALUNYA 1989, 1993; SONDEIG D’OPINIÓ CATALUNYA 2007, 2008). Las últimas estadísticas del año 2011 mostraban que la evolución negativa continúa en Catalunya, disminuyendo el porcentaje de Católicos hasta el 58,1\% (SONDEIG D’OPINIÓ CATALUNYA 2011, 2012). El 69\% de los encuestados se definieron como creyentes, siendo de estos el 58\% Católicos y un $11 \%$ de otras religiones. Aquellos que se definieron como no creyentes son el 22,4\% y ateos el 7,3\%. De aquellos autoadscritos al catolicismo sólo un 19\% asisten a misa casi todos los domingos o varias veces a la semana, siendo un total de $80,9 \%$ aquellos que no asisten nunca a misa o alguna vez al mes o al año (SONDEIG D'OPINIÓ CATALUNYA 2011, 2012). Más significativo era el grado de apreciación que los ciudadanos mostraban por la Iglesia católica, la peor valorada con un mayor voto negativo del $23,7 \%$ seguido por la siguiente peor valoración de la actuación del gobierno central de España con un 15,4\%. No tenemos datos del desglose entre practicantes y no practicantes para el año 2011 pero si mantenemos los datos del 2007 y los comparamos con los del 2011, tenemos que destacar que el número de no creyentes y ateos es aproximadamente tres veces superior al 
número de católicos practicantes. Así, para Catalunya, vemos como una parte ínfima de la sociedad continúa con creencias religiosas, aunque habría que matizar que la autoadscripción como católico practicante no es sinónimo de individuo sujeto a sistema de creencias, sin embargo no tenemos mejores datos y en este caso los continuamos utilizando como una aproximación, aunque como veremos, fácilmente cuestionables por los datos más desglosados que presentamos a continuación sobre España.

Así, las estadísticas respecto a la situación de las creencias en España nos permiten un análisis más pormenorizado, al poder valorar además de los porcentajes de autoadscripción (como hemos visto en el caso de Catalunya), las valoraciones e interpretaciones de la realidad de los ciudadanos, es decir, nos permiten investigar si siguen cánones de los sistemas de creencias o no, y además nos permiten profundizar en el sometimiento a las creencias de la doctrina católica y compararlo con otras creencias ancestrales con las que coexisten. En el año 2010, el 74\% de los entrevistados se declararon católicos, de estos el 84,3\% de los encuestados no asisten nunca a misa, varias veces al año o alguna vez al mes, el 14,9\% asiste al menos una vez a la semana (CIS, 2010). Un total de $22,4 \%$ son no creyentes $(15,2 \%)$ y ateos (7,2\%). Así, España es un país donde la mayoría católica domina, aunque estos datos del 2010 no nos muestran el desglose entre aquellos que se autoadscriben como practicantes o no practicantes. Entonces, podríamos suponer que las creencias asociadas a esta religión serían las que los españoles defienden. El argumento que presentamos tiene dos niveles, uno valoral y otro interpretativo. Así, el primer nivel de análisis reside en comprender qué relación existe entre auto-definirse como católico y las actitudes y valoraciones que los ciudadanos defienden, veremos que no existe una relación directa positiva. En el segundo nivel intentamos comprender si las diversas interpretaciones que se ofrecen de las realidades del mundo son las que los ciudadanos aceptan, utilizando como referencia creencias de la Iglesia católica y otras creencias. 
En el primer nivel analizaremos las valoraciones respecto a varias cuestiones extraídas de dos estudios, con el fin de observar el sentido de la evolución si lo hubiere, elaborados por el Centro de Investigaciones Sociológicas en el año 1998 y 2008 (CIS, 1998; CIS, 2008):

- ¿Considera que está mal que un hombre y una mujer tengan relaciones sexuales antes del matrimonio? En el año 1998 un 61,2\% de los entrevistados opinaban que nunca está mal, aumentando un 10\% hasta el $67,5 \%$ en el año 2008. Al mismo tiempo aquellos que opinaban que siempre está mal habían disminuido un 32\% hasta significar el 10,2\% de la población en el 2008.

- ¿Cómo valora las relaciones sexuales entre dos adultos del mismo sexo? Un 45,2\% en el año 1998 pensaban que nunca están mal, ascendiendo un $14 \%$ hasta el 51,6\% en el 2008. También se apreciaba una significante reducción del $17 \%$ de aquellos que pensaban que siempre está mal, alcanzando un 24,8\% en 2008

- ¿Cree Ud. personalmente que una mujer tenga un aborto voluntario si resulta muy probable que el bebé padezca algún defecto importante es...? Un 58,4\% consideran que nunca está mal, y un 15,9\% considera que siempre está mal en 1998, manteniéndose relativamente estable el primer porcentaje en el 2008 y disminuyendo un $14 \%$ el segundo para este mismo año.

- ¿Está de acuerdo que la responsabilidad del marido consiste en ganar dinero, la de la mujer, en cuidar de la casa y de la familia?. Un 31,9 \% estaba muy en desacuerdo con esta afirmación en el 1998 aumentando un 61\% hasta alcanzar el 51,5\% en el año 2008.

- ¿Qué grado de confianza le inspira a Ud. la iglesia y las organizaciones religiosas?, el $44 \%$ de los entrevistados daban poca confianza o ninguna 
confianza a la Iglesia y organizaciones religiosas en el año 2008, respecto a aquellos que tenían toda o mucha confianza un $28 \%$.

- ¿En qué medida está Ud. de acuerdo o en desacuerdo con que las autoridades religiosas no deberían influir en lo que la gente vota en las elecciones? un $78 \%$ estaba muy de acuerdo o de acuerdo con esta afirmación en el 1998, aumentando hasta el 81,6\% en el año 2008 .

- ¿Observando lo que pasa en el mundo, las religiones son más fuente de conflictos que de paz? Ha aumentado en un 18\% el número de personas que está muy de acuerdo o de acuerdo con esta afirmación pasando del $48 \%$ en 1998 al 56\% en el año 2008.

- ¿Los muy creyentes son a menudo demasiado intolerantes con los demás? un $56,9 \%$ estaban de acuerdo o muy de acuerdo con esta afirmación en el año 1998, creciendo un 4\% hasta alcanzar un 60,5\% en el año 2008.

- La iglesia y las organizaciones religiosas de España tienen un poder desmesurado o demasiado poder según el 41,6\% de los encuestados en el 1998. Aumentando un 23\% hasta alcanzar un 51,3\% en el año 2008.

Las cifras muestran como los individuos encuestados presentan unas opiniones alejadas del sistema de valoración de las creencias católicas, y aunque se muestra una clara evolución negativa en la importancia de las valoraciones provenientes de este sistema religioso todavía se considera que su importancia es desmesurada.

Las estadísticas confeccionadas por el Obradoiro de Socioloxia (ZAGARRÁ, 2008) nos permiten profundizar en la relación entre la creencia y la autoadscripción de los encuestados y también profundizar en la noción de 
creencia, en el segundo nivel, como interpretación de la realidad. Así, en el año 2008 un total de 80,5\% de los encuestados se declaraban católicos, de estos 29,2\% se reconocían practicantes y un 51,3\% no practicantes. Había un 2\% de creyentes de otras religiones y un total de $16,5 \%$ que se desglosaban en no creyentes 8,9\%, y ateos un 7,6\%. El estudio analizaba las creencias de los españoles agrupadas según fuera su adscripción como católico practicante, no católico o no creyente (se incluyen en esta partida los ateos). La principal conclusión del estudio es que sólo un $22 \%$ de los que se consideran católicos practicantes, que ascendía a un total de $29.2 \%$, creen en las creencias propugnadas por la Iglesia católica. Así aquellos católicos fieles a la tradición serían sólo el 6\% de la población española. Si bien es cierto que las personas viven, interiorizan y valorizan su religión de distinta manera, los datos aportados describen como sólo un 6\% de la población española potencialmente vive, interioriza y valoriza la religión católica dentro del ámbito de sistema axiológico heterónomo de creencias propugnado por la Iglesia Católica. Esto es así, porque aunque estadísticamente muchos se autoadscriben como católicos practicantes, en un gran porcentaje no aceptan creencias básicas de este sistema axiológico heterónomo propugnado por la Iglesia Católica. Por tanto, el sistema heterónomo de creencias no está vigente aunque los mismos individuos puedan describirse como creyentes católicos practicantes. A modo de ilustración, con el fin de clarificar como interpretan la realidad presentamos las siguientes cifras de los que se autodenominan como católicos practicantes (un $\mathbf{2 9 , 2 \% ~ d e ~ l o s ~}$ entrevistados en el año 2008): 


\section{Tabla 5}

\section{La "descreencia" de los Católicos Practicantes Españoles}

\begin{tabular}{|l|c|}
\hline No creen o dudan que Jesús fuera un personaje histórico que existió realmente & $6 \%$ \\
\hline No creen o dudan que Jesús era Dios o hijo de Dios & $15 \%$ \\
\hline No creen o dudan que Jesús nació de una virgen & $19 \%$ \\
\hline No creen o dudan que fueron tres reyes de oriente a visitarle & $29 \%$ \\
\hline No creen o dudan que Jesús después de morir resucitó & $17 \%$ \\
\hline No creen o dudan en los milagros & $33 \%$ \\
\hline No creen o dudan que Dios creó el mundo de la nada & $32 \%$ \\
\hline No creen o dudan que Adán y Eva fueron los primeros seres humanos & $42 \%$ \\
\hline No creen o dudan que existe el infierno & $51 \%$ \\
\hline No creen o dudan que existe el cielo & $29 \%$ \\
\hline No creen o dudan que el alma vive después de la muerte & $28 \%$ \\
\hline No creen o dudan que existe el demonio & $45 \%$ \\
\hline No creen o dudan que exista Dios & $11 \%$ \\
\hline
\end{tabular}

Fuente: ZAGARRÁ, 2008

Se podría argumentar que el estudio de Zagarrá presenta un problema, ya que el investigador coloca en el mismo esquema interpretativo las opciones de no creer y dudar. Sin embargo, si se podría afirmar que el hecho de dudar de una creencia ya está implicando de alguna manera que ésta es más débil y que no afecta al pensar, sentir y actuar, con tanta fuerza como es una creencia heterónoma, estando pues en la misma línea que las creencias autónomas. Por tanto, creemos que se puede defender que aunque a diferentes niveles, las opciones de no creer y dudar, significan ambas que la creencia heterónoma ya no es vivenciada.

Como vemos, la autoadscripción como católico practicante no nos dice mucho respecto al nivel de sumisión a las creencias heterónomas propugnadas por la Iglesia. Es a partir de un análisis más pormenorizado que entendemos el concepto de creencia, y vemos como el sistema de creencias heterónomo no está 
tan vigente como el número de auto-definidos creyentes pareciera describir. Las cifras para los creyentes no practicantes muestran un nivel de adhesión al sistema heterónomo de creencias todavía menor. Así, los católicos no practicantes presentan cifras más elevadas en su "descreencia” destacando que un $46 \%$ de estos católicos no practicantes no creen en la existencia de Dios, un 54\% que Jesús no era Dios o que no nació de una virgen un 65\%. Podemos entonces argumentar que su adscripción como católicos es meramente parte de su identidad tradicional, no están realmente sujetos a un sistema de creencias religioso, o siendo más radicales, podríamos afirmar que su adscripción como católicos no tiene ningún sentido religioso.

El estudio también presenta datos sobre otro tipo de creencias más ancestrales. Destacamos que la relación entre ser practicante o no de la fe católica no presenta una diferencia significativa en el grado de creencia de estas creencias más ancestrales y variopintas, aunque los católicos en su conjunto sí presentan porcentajes relativamente superiores a los no creyentes.

\section{Tabla 6}

\section{Creencias según sean católicos practicantes, católicos no practicantes o no creyentes}

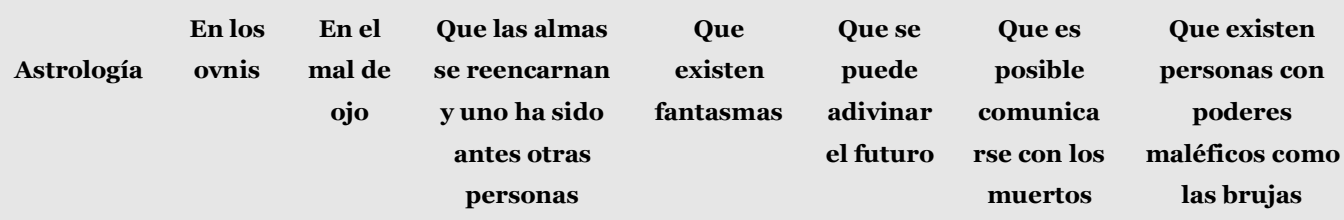

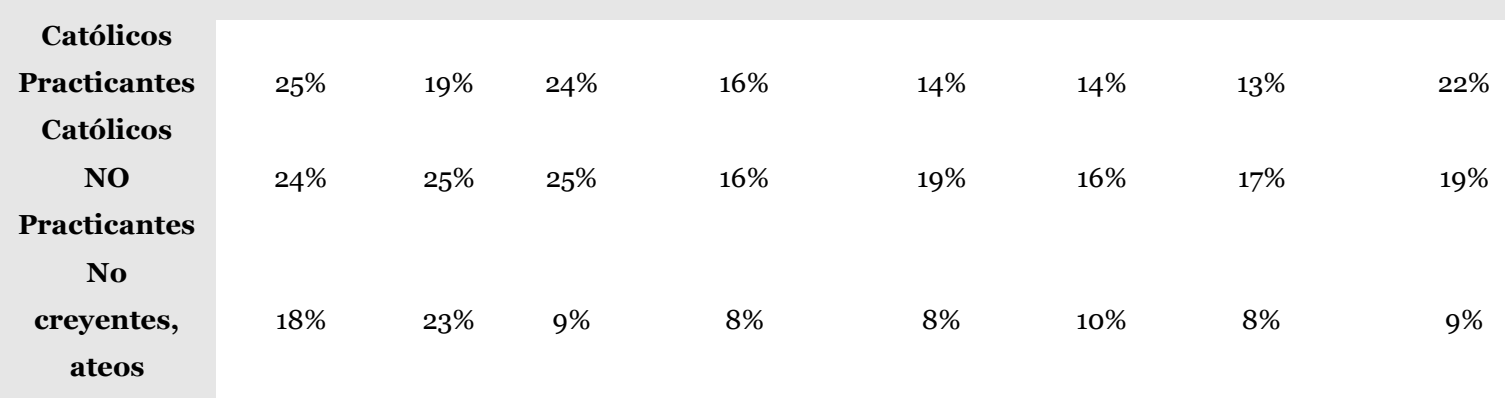

Fuente: ZAGARRÁ, 2008 
Estas cifras muestran una vez más la total desarticulación de las creencias provenientes de la religión católica. También manifiestan la coexistencia de diversos tipos de creencias ancestrales y variopintas con aquellas de la iglesia católica. Además, los porcentajes de estas creencias variopintas como por ejemplo, la astrología con un 22,6\%, el mal de ojo con un 21,3\% y la creencia en las brujas con un 17,7\% de adscripción, son superiores al 6\% de los encuestados que se someten a las creencias de la Iglesia católica.

A continuación, estaríamos interesados en investigar la posible proyección futura de los datos sobre creencias. Así, nos centramos en las estadísticas de los jóvenes españoles (FUNDACIÓN SM, 2010). Vemos que en el año 2010, un 53,5\% de los jóvenes de entre 15-24 años se definían como católicos, datos que contrastan con el 74\% de la población general mencionados anteriormente. De estos, la proporción de practicantes/no practicantes no está desglosada. Podríamos estimar la proporción de practicantes atendiendo a la práctica religiosa, aunque sin duda no sea suficiente para justificar si se sigue con la práctica religiosa. Sólo un 9\% de los jóvenes va a misa por lo menos una vez a la semana y un 5\% afirma acudir una vez al mes, así podríamos pensar que la proporción de practicantes es muy pequeña. Un $42 \%$ de los jóvenes se declaraba no religioso (16\% indiferentes, 9\% agnósticos, 17\% ateos) frente a un 22,4\% de la población general. Una diferencia sustancial que permite proyectar una disminución progresiva del sistema de creencias de las religiones para la población española.

Sólo un 3\% de los encuestados afirma que las interpretaciones del mundo de la Iglesia son importantes y significativas, es decir, lo que diga la Iglesia no cuenta verdaderamente, no es significativo para el 97\% restante. De hecho, la iglesia ocupa el último lugar en las valoraciones de los encuestados. Aspectos importantes de la vida $\quad(1=$ nada importante - hasta 4 = muy importante $)$ : 


\section{Tabla 7}

\section{Valoraciones de los aspectos importantes de la vida para los jóvenes}

(1 = nada importante - hasta 4 = muy importante):

\begin{tabular}{|c|c|}
\hline Familia & 3,66 \\
\hline Salud & 3,62 \\
\hline Amigos y conocidos & 3,51 \\
\hline Ganar dinero $^{\prime}$ & 3,31 \\
\hline Tiempo libre/ocio $^{1}$ & 3,33 \\
\hline Trabajo & 3,26 \\
\hline Estudios-formación y competencia profesional & 3,15 \\
\hline Vida moral y digna $^{\prime}$ & 3,21 \\
\hline Pareja & 3,19 \\
\hline Vida sexual satisfactoria & 3,01 \\
\hline Política & 1,95 \\
\hline Religión & 1,81 \\
\hline
\end{tabular}

Fuente: FUNDACIÓN SM, 2010

Estas valoraciones negativas se sustantivan con las siguientes opiniones de los jóvenes: Un $64 \%$ opina que la Iglesia se mete demasiado en política, un $75 \%$ que tiene una postura anticuada en referencia a la vida sexual, un $63 \%$ que se mete demasiado en la vida privada de la gente diciéndole como tiene que vivir su vida y el $58 \%$ que las directrices de la iglesia dificultan disfrutar de la vida. En el extremo positivo, sólo un 40\% afirman que las normas de la Iglesia ayudan a vivir más moralmente y sólo un $45 \%$ que la Iglesia ofrece un hogar espiritual y sinceramente religioso. Así, vemos que el aspecto moral de la doctrina católica continúa siendo valorado.

Casi un 32\% de los jóvenes españoles se declaraban miembros de la Iglesia, y un 53\% estaba de acuerdo en que se puede ser miembro de la Iglesia sin seguir todas sus directrices. Así, en referencia a las creencias, es interesante

\footnotetext{
${ }^{1}$ Pareciera que hay un error en las estadísticas utilizadas, que no hemos podido comprobar, ya que se presentan en orden decreciente de valoración y sin embargo en el caso de Ganar dinero y Tiempo libre/ocio, igualmente en el caso de Estudios, Vida moral y digna y Pareja, están presentados en orden inverso.
} 
destacar que sólo la creencia en la existencia de Dios es mayoritaria. Otras presentan porcentajes inferiores al 30\% como la creencia que Jesucristo es Dios (31\%), en la reencarnación $(19,8 \%)$ en la resurrección de los muertos $(18,8 \%)$, en el pecado (29\%) en la resurrección de Jesucristo (28\%), en la vida después de la muerte (28,2\%) (ZAGARRÁ, 2008).

También estaríamos interesados en conocer las valoraciones de los jóvenes en referencia a cuestiones que afectan a como viven su vida, tal como vimos para la población adulta. De un estudio diferente de los jóvenes españoles, que se centra específicamente en universitarios (FUNDACIÓN BBVA, 2005) destacamos la siguiente tabla que muestra la aceptación mayoritaria y significativa de cuestiones que no están tan aceptadas en la mayoría de los adultos y que van en contra de las doctrinas de la Iglesia.

\section{Tabla 8}

\section{Pueden estar justificados los siguientes comportamientos?}

$\begin{aligned} & \text { Tabla 25. Con independencia de lo que fú haces o harías, crees que puede estar justificado cada una } \\
& \text { de las cosas que fe leo. }\end{aligned}$
\begin{tabular}{l|c} 
Base: total de casos (3000); Media en una escala de 0 a 10 (0 significa que nunca se puede justificar y \\
10 que siempre se puede justificar)
\end{tabular}
\begin{tabular}{l|c} 
Vivir en pareja sin casarse & 8.8 \\
\hline $\begin{array}{l}\text { Recurrir a técnicas de reproducción asistida para que las parejas con problemas de } \\
\text { infertilidad puedan tener un hijo }\end{array}$ & 8.4 \\
\hline El matrimonio entre personas del mismo sexo & 7.9 \\
\hline Ser padre o madre sin tener pareja estable & 7.8 \\
\hline La eutanasia (asistir a alguien a morir cuando tiene una enfermedad incurable) & 7.0 \\
\hline El aborto & 6.8
\end{tabular}

Fuente: FUNDACIÓN BBVA, 2005

Este mismo estudio destaca que sólo un 33\% considera importante marcar momentos claves de la vida como el nacimiento, matrimonio y muerte con ceremonias religiosas. Es decir, una gran mayoría de los encuestados jóvenes, el 67\%, no lo considera relevante. También puntualizamos que de este 33\% no sabemos el porcentaje que lo encuentra relevante como perpetuación de una tradición o aquellos que verdaderamente viven sometidos a las creencias católicas. 


\section{Conclusión}

Con este escrito hemos pretendido clarificar por medio de datos estadísticos como los sistemas heterónomos de creencias no están vigentes en la actualidad. Esta afirmación no es nueva (ARTS; HALMAN, 2004. ESTER; MOHLER; VINKEN, 2006), la aportación del escrito consiste en utilizar estadísticas recientes de España para describir esta afirmación detalladamente a través de las afirmaciones de los encuestados.

La interpretación y uso de estas estadísticas nos han permitido clarificar la noción de creencia. Así, hemos argumentado que cuando se habla de creencia religiosa o ideológica en un elevado porcentaje se trata de creencias autónomas en la misma línea que creencias acríticas, que nosotros hemos denominado supuestos acríticos. Por tanto, no son las creencias propugnadas por los sistemas axiológicos heterónomos de la religión y las ideologías.

La presentación de tres encuestas del Banco Mundial nos ha permitido ligar una posibilidad apuntada por estas tres significativas encuestas que torpedean elementos del sistema axiológico proveniente de las religiones para posteriormente con análisis estadísticos más detallados pasar a comprender la realidad española y catalana.

Así de este estudio axiológico limitado a España y Cataluña podemos afirmar que el sistema axiológico heterónomo proveniente de las religiones no está vigente a nivel social, esto no quiere decir que a nivel individual no se expresen creencias.

Hemos considerado que puedan existir aumentos de las religiones en sociedades con sistemas de vida industrial o pre-industrial. También hemos considerado la posibilidad que puedan existir aumentos de ciertas religiones en sociedades heterogéneas, pero estos aumentos serán a costa de otras religiones y en relación a la totalidad serán marginales dada la extensión de la globalización y el proceso de individualización asociado. 
Hemos reflexionado como las religiones en el siglo XXI, aunque siguen funcionando como sistemas heterónomos no son, con excepciones, impuestos socialmente. Por tanto, la fuerza de estas creencias heterónomas no será tan fuerte como los de la sociedades industriales y pre-industriales.

Hemos demostrado, utilizando las estadísticas de Catalunya y de España, que los sistemas axiológicos de creencias basados en la religión no están vigentes. Así, las estadísticas del 2010 en Catalunya mostraban un 12,5\% de católicos practicantes, y en el 2008 se estimaba que en España sólo había un total del $6 \%$ de la población que eran practicantes y creían las principales creencias de la Iglesia. Por tanto, los sistemas heterónomos de creencias están vigentes en diferentes maneras vivenciales para el $6 \%$ de la población española. Los números son claros, la población está desarticulada axiológicamente, no tenemos sistemas de creencias que determinen la vida del individuo colectivamente. Si las estadísticas para los adultos ya eran reveladoras, aquellas de la población juvenil muestran una disminución acusada, alejada de cualquier determinación heterónoma, existiendo una diferencia de más de 20 puntos en relación a la población adulta ( $74 \%$ vs. 53,5\% autoadscritos como católicos, $22 \%$ vs. $42 \%$ autoadscritos como no religiosos).

Hemos clarificado la noción de creencias versus diversas acepciones de creencia. Así, las creencias, que provienen de las religiones o de las ideologías, son heterónomas y socialmente impuestas con mayor o menor fuerza. Estas creencias determinan, fijan la vida del individuo, su pensar y su sentir. Las otras diversas acepciones de creencias son aquellas que no fijan, son idiosincrasias personales, elecciones autónomas que pueden bien provenir de sistemas religiosos o de otros sistemas tradicionales ancestrales. Sin embargo, la gran mayoría de lo que se denominan creencias se presentan bajo la forma de supuestos acríticos. También hemos clarificado la noción de creencia utilizada en el lenguaje común y la utilizada en la retórica del lenguaje científico. Por tanto, sería siempre necesario definir antes de expresarse a que noción de 
creencia nos referimos con el fin de no inducir a equívoco. Así, para nosotros las creencias serían sólo aquellos preceptos y valores colectivos legitimados por una autoridad divina, o descubiertos en la naturaleza de las cosas en el caso de las ideologías.

Hemos profundizado en la relación entre autoadscribirse como perteneciente a Iglesia católica y las creencias que se poseen. Hemos mostrado que no existe relación entre lo uno y lo otro, o mejor dicho que la totalidad de las creencias de la Iglesia, que proporcionan una interpretación y valoración de la realidad no son defendidas en España, según estimaciones del 2008, por un 94\% de los encuestados.

Por tanto, si los sistemas axiológicos de los individuos no vienen determinados por las creencias de las religiones que proporcionaban una cierta calidad humana, entonces la pregunta que nos hacemos es ćcómo conseguimos educar individuos, en el siglo XXI, que sean capaces de crear proyectos de vida, proyectos humanos que valgan la pena, con calidad?, es decir, ¿cómo desarrollamos sistemas axiológicos que sean capaces de cohesionar y motivar a los individuos hacia fines valiosos comunes? Y al mismo tiempo ¿cómo cultivamos el desarrollo de la calidad humana que emana de las religiones y las tradiciones de sabiduría sin aferrarnos a sus sistemas axiológicos?. Aquí está el reto.

\section{REFERENCIAS}

ARTS, W.; HALMAN, L. European values at the turn of the millenium: an introduction. In W. Arts \& L. Halman (Eds.). European values at the turn of the millenium. Leiden/ Boston: Brill, 2004.

AUGÉ, M. Los no lugares. Espacios del anonimato. Una antropología de la sobremodernidad. Barcelona: Gedisa, 2000.

BAUMAN, Z. Modernidad Líquida. Buenos Aires: Fondo de Cultura Económica, 2004. 
BECK, U. ¿Qué es la globalización?. Falacias del globalismo, respuestas a la globalización. Barcelona: Paidós, 1998.

BECK, U. Risk Society, Towards a New Modernity. London: Sage Publishers, 1992.

BECK, U.; BECK-GERNSHEIM, E. Individualization. Institutionalized Individualism and its social and political consequences. London: Sage, 2001.

CIS. CENTRO DE INVESTIGACIONES SOCIOLÓGICAS. Barómetro de julio. Estudio n. 2.843, jul. 2010. Disponible en: <http://www.cis.es/cis/opencms/-

Archivos/Marginales/2840_2859/2843/es2843.pdf>. Acceso en: 14 feb. 2011

CIS. CENTRO DE INVESTIGACIONES SOCIOLÓGICAS. Religión - International

Social Survey Programme (ISSP). Estudio n. 2.301, sept. 1998. Disponible en: <http://www.cis.es/cis/export/sites/default/-

Archivos/Marginales/2300_2319/2301/Es2301mar.pdf>. Acceso en: 14 nov. 2010

CIS. CENTRO DE INVESTIGACIONES SOCIOLÓGICAS. Religión (II) ISSP -

International Social Survey Programme (ISSP). Estudio n. 2.776, oct./dic. 2008.

Disponible en: <http://www.cis.es/cis/export/sites/default/-

Archivos/Marginales/2760_2779/2776/es2776.pdf>. Acceso en: 14 nov. 2010

EIBL-EIBESFELDT, I. La Sociedad de la desconfianza. Barcelona: Herder, 1996.

ELIAS, N. La sociedad de los individuos. Barcelona: Ediciones Península, 1990.

ESTER, P.; MOHLER, P.; VINKEN, H. Values and the social sciences: A global world of global values? In P. Ester \& M. Braun \& P. Mohler (Eds.), A cross-national and intergenerational perspective. Leiden/Boston: Brill, 2006.

FUNDACIÓN BBVA. Segundo Estudio de la Fundación BBVA sobre los Universitarios Españoles. Nota de Prensa. 2005. Disponible en:

<http://www.fbbva.es/TLFU/dat/np_universitarios.pdf>. Acceso en: 7 nov. 2010

FUNDACIÓN SM. Jóvenes españoles 2010. Sala de Prensa 24 nov. 2010. Madrid, Fundación SM, 2010. Disponible en: <http://prensa.grupo-sm.com/2010/11/casi-lamitad-de-los-j\%C3\%B3venes-espa\%C3\%B1oles-declara-su-falta-de-confianza-en-unfuturo-prometedor-para-el.html>. Acceso en: 9 ene. 2011

GEERTZ, C. Available Light. Anthropological reflections on philosophical topics. New Jersey: Princeton University Press, 2000.

GIDDENS, A.; BAUMAN, Z.; LUHMANN, N.; BECK, U. Las consecuencias perversas de la modernidad. Barcelona: Anthropos, 1996.

HOBSBAWN, E. Historia del siglo XX. Buenos Aires: Crítica, 1998. 
McGOWAN, D.; MATSAMURA, M.; METSKAS, A.; DEVOR, J. Raising Freethinkers. A Practical Guide for Parenting Beyond Belief. New York: American Management Association (Amacom), 2009.

SONDEIG D’OPINIÓ CATALUNYA 1989. Barcelona: Institut de Ciències Polítiques i Socials. Adscrit a la Universitat Autònoma de Barcelona, 1993. Disponible en: <http://www.icps.cat/archivos/sondeigs/SC1989.pdf>. Acceso en: 7 nov. 2010

SONDEIG D’OPINIÓ CATALUNYA 2007. Barcelona: Institut de Ciències Polítiques i Socials. Adscrit a la Universitat Autònoma de Barcelona, 2008. Disponible en: <http://www.icps.cat/archivos/sondeigs/SC2007.pdf>. Acceso en: 10 jul. 2010

SONDEIG D’OPINIÓ CATALUNYA 2010. Barcelona: Institut de Ciències Polítiques i Socials. Adscrit a la Universitat Autònoma de Barcelona, 2011. Disponible en: <http://www.icps.cat/archivos/sondeigs/SC2010catala.pdf>. Acceso en: 14 feb. 2011

SONDEIG D’OPINIÓ CATALUNYA 2011. Barcelona: Institut de Ciències Polítiques i Socials. Adscrit a la Universitat Autònoma de Barcelona, 2012. Disponible en:

<http://www.icps.cat/archivos/sondeigs/SC2011catala.pdf>. Acceso en: 11 sep. 2012

THE WORLD BANK. World Development Indicators 2011. Disponible en: <http://data.worldbank.org/data-catalog/world-development-indicators/wdi-2011>. Acceso en: 6 dic. 2010

ZARRAGÁ, José Luis de. La fe española hace aguas. Publico.es. Publiscopio. Madrid, 26 dic. 2008. Disponible en: <http://www.publico.es/espana/186215/la-fe-espanola-haceaguas $>$. Acceso en: 10 nov. 2010 